Review

\title{
Cerebral Sulcal Asymmetry in Macaque Monkeys
}

\author{
Kazuhiko Sawada
}

Department of Nutrition, Faculty of Medical and Health Sciences, Tsukuba International University, Tsuchiura, Ibaraki 300-0051, Japan; k-sawada@tius.ac.jp; Tel.: +81-29-883-6032

Received: 24 August 2020; Accepted: 11 September 2020; Published: 14 September 2020

\begin{abstract}
The asymmetry of the cerebral sulcal morphology is particularly obvious in higher primates. The sulcal asymmetry in macaque monkeys, a genus of the Old World monkeys, in our previous studies and others is summarized, and its evolutionary significance is speculated. Cynomolgus macaques displayed fetal sulcation and gyration symmetrically, and the sulcal asymmetry appeared after adolescence. Population-level rightward asymmetry was revealed in the length of arcuate sulcus (ars) and the surface area of superior temporal sulcus (sts) in adult macaques. When compared to other nonhuman primates, the superior postcentral sulcus (spcs) was left-lateralized in chimpanzees, opposite of the direction of asymmetry in the ars, anatomically-identical to the spcs, in macaques. This may be associated with handedness: either right-handedness in chimpanzees or left-handedness/ambidexterity in macaques. The rightward asymmetry in the sts surface area was seen in macaques, and it was similar to humans. However, no left/right side differences were identified in the sts morphology among great apes, which suggests the evolutionary discontinuity of the sts asymmetry. The diversity of the cortical lateralization among primate species suggests that the sulcal asymmetry reflects the species-related specialization of the cortical morphology and function, which is facilitated by evolutionary expansion in higher primates.
\end{abstract}

Keywords: non-human primate; Old World monkey; evolution; evolutionary expansion; gyrification

\section{Introduction}

Brain lateralization has been reported in many species including vertebrates and invertebrates [1]. The gyrencephalic surface morphology is a distinctive feature of the cerebral cortex seen in some mammalian species including humans [2], nonhuman primates [3-5], carnivores [3,6-9], artiodactyla [3,10] and cetaceans $[11,12]$. The cerebral sulcal morphology in primates is largely influenced by genetic factors that manifest during the second-trimester equivalent $[13,14]$, and is modified under the influences of developmental and environmental factors during the third-trimester equivalent to form adult features $[15,16]$. In particular, the cortical expansion, known as one of the developmental factors, is closely correlated with gyrification across primate species $[17,18]$ and is involved in species-related patterns of sexual dimorphism and/or individual variability of the sulcal morphology $[19,20]$.

Cerebral sulci are highly lateralized in humans. Leftward sulcal asymmetry reported in the central sulcus (cs) is associated with handedness [21,22]. Additionally, leftward sulcal asymmetry in the paracingulate sulcus has been linked with cognition [23,24], while rightward sulcal asymmetry in the superior temporal sulcus (sts) is relevant to fMRI-defined right-lateralized voice selective responses $[25,26]$. Cortical lateralization, along with sulcal asymmetry, has been classically considered to be a unique characteristic in humans [27]. However, sulcal asymmetry has been observed in nonhuman primates such as great apes [28,29] and macaque monkeys [29]. This report summarizes the results of our studies and other findings regarding the laterality of sulcal infolding in the cerebral cortices of macaque monkeys - a genus of the Old World monkeys. The pattern of sulcal asymmetry in macaques to other primates was compared to speculate on the evolutionary significance of the sulcal 
asymmetry in primates. The sulcal asymmetry of the macaque brain and its related characteristics are summarized in Figure 1 in comparison to other primate species.

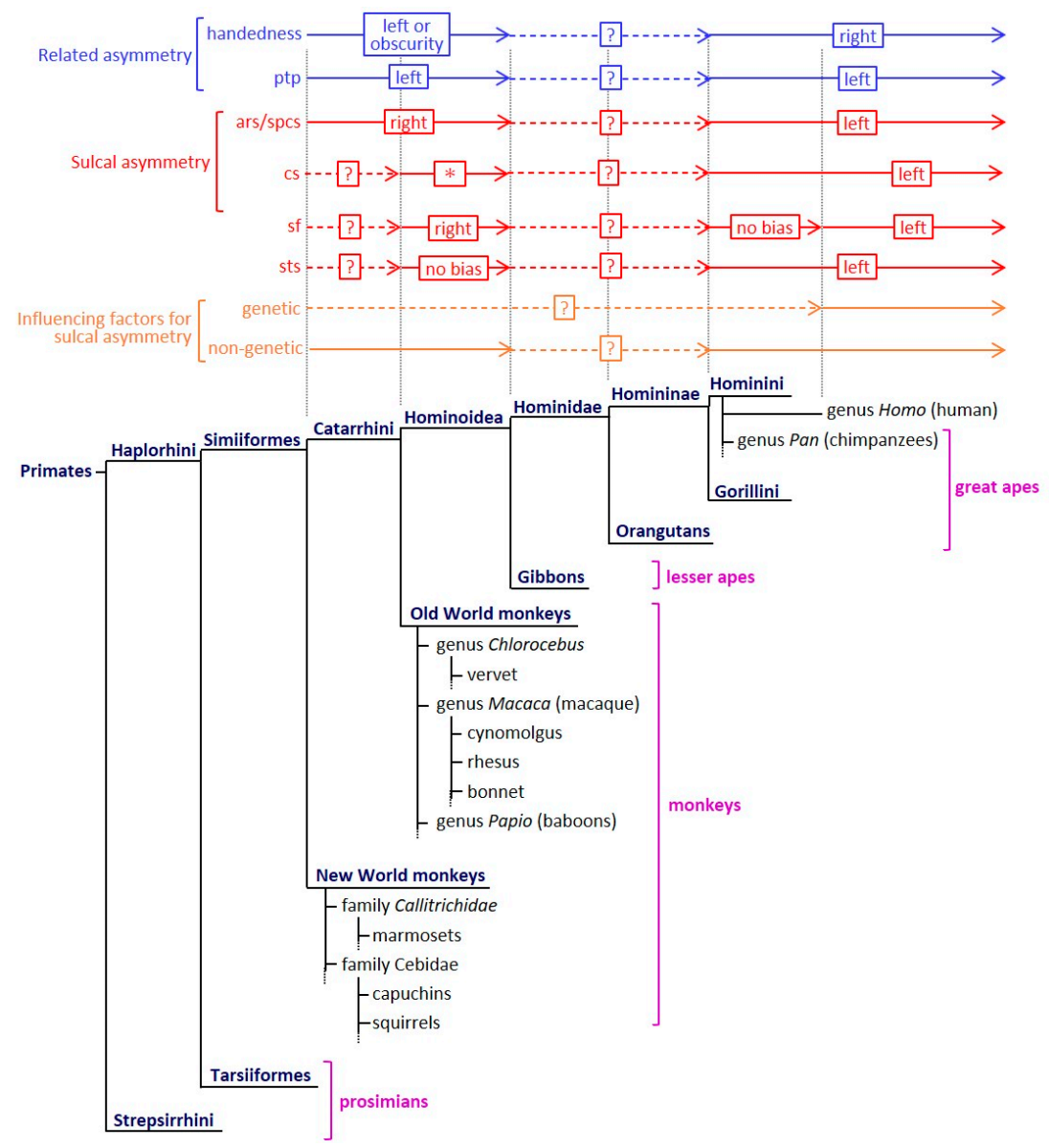

Figure 1. The evolution of sulcal asymmetry and its related asymmetrical characteristics among primate species. The sulcal asymmetry, its related asymmetrical characteristics, and influencing factors for sulcal asymmetry are summarized in reference to previous reports $[4,5,13,20,28-47]$. An asterisk $\left(^{*}\right)$ indicates that the cs symmetry is inconsistent in the Old World monkeys. The presence or absence and the direction of cs asymmetry vary depending on the species. ars, arcuate sulcus; cs, central sulcus; ptp, planum temporale; sf, Sylvian fissure; spcs, superior prefrontal sulcus; sts, superior temporal sulcus.

\section{Asymmetrical Development of Cerebral Sulci}

Sulcal morphology is influenced by genetic, developmental, and environmental factors [15,30]. In humans, the cs and sts emerge earlier on the right side compared to the left side during fetal development [2,31], which suggests a large influence of genetic factors on the asymmetric sulcal emergence. On the other hand, the sulcal length and depth were variable after birth in the baboon, a genus of the Old World monkeys [13]. Furthermore, sulcal infolding in multimodal association cortices was highly correlated with cortical expansion in cynomolgus macaques [16]. These findings suggest the possibility that the sulcal morphology in the Old World monkeys is modified after birth under the influences of developmental and environmental factors. Cynomolgus macaques experienced fetal sulcation and gyration symmetrically $[4,32]$ and showed the sex-related appearance of sulcal asymmetry after adolescence $[20,33]$. Thus, sulcal asymmetry in the Old World monkeys may be largely attributed to environmental and developmental factors rather than genetic factors.

Although the New World monkeys are secondarily lissencephalic with reductions in body and brain sizes compared to their gyrencephalic ancestors [48], several primary sulci are sustained [5]. 
The cs, sts, and the parietooccipital sulcus emerged in adult common marmosets as small indentations, separately, on the left and right sides [5]. The incidence of each sulcus emerging was not biased between the left and light cerebral hemispheres [5], thus suggesting the individual variability of the emergence of asymmetric sulci. Therefore, the shift of nongenetic factor-related sulcal asymmetry from individual to population-level variabilities may appear before the split between the New World monkeys and Old World monkeys. Furthermore, the genetic factor-related sulcal asymmetry may occur after the split between the Old World monkeys and humans.

\section{Sulcal Asymmetry in Macaques}

The sulcal length asymmetry in macaques has been reported for more than three decades [49-53]. However, these studies failed to obtain consistent results. One possible reason for these discrepancies is that several of these studies used mixed-sex and/or -species samples for measurements of the sulcal lengths. After separating male and female cynomolgus macaques, we measured the sulcal lengths of left and right cerebral hemispheres and found the right-lateralization of the arcuate sulcus (ars) length in males, but not in females [20], following puberty [33]. The AQ values of eight representative primary sulci in our previous report [20] were analyzed using a one-sample $t$-test to determine significant-population level asymmetry of the sulcal lengths in cynomolgus macaques. A significant right-bias of $A Q$ values $(0.053 \pm 0.069)$ was only identified after examining the ars length in adult males $(p<0.05)$. A sulcal map of the left and right cerebral hemispheres in cynomolgus macaques is shown in Figure 2. The ars in macaques is infolded in the lateral frontal cortex and identified as the early-emerging sulcal groups, which emerged in cynomolgus macaques between embryonic days 70 to 120 of the 160 day-long gestational period [4,32]. The cs, sts, and cingulate sulcus also appeared during this time $[4,32]$. However, the ars morphology in the Old World monkeys was greatly influenced by environmental factors rather than genetic factors, unlike the morphologies of other early-emerging sulci [13].

(a)

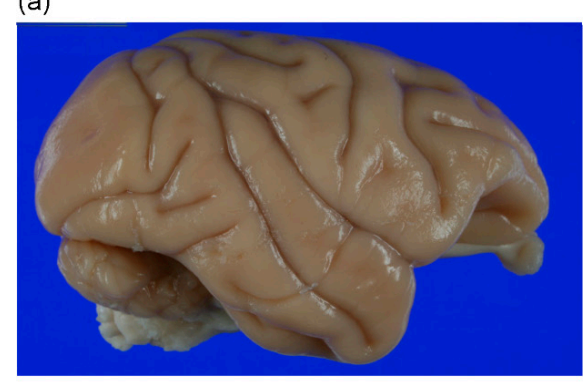

(c)

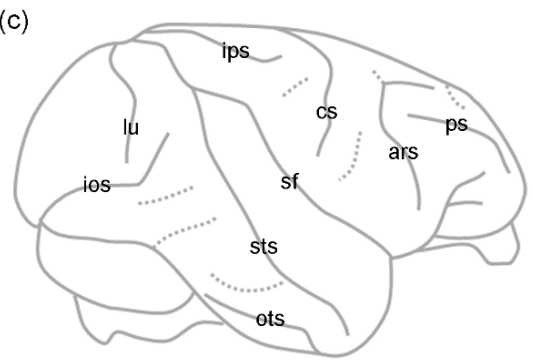

(b)

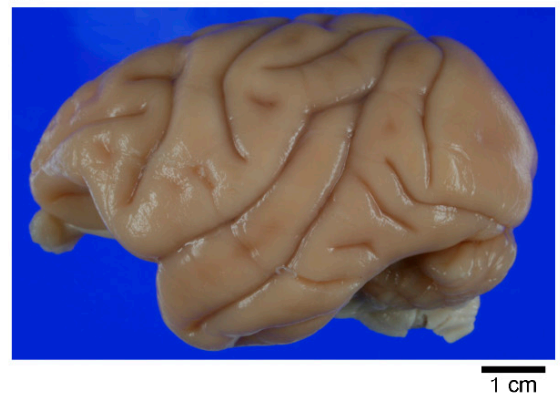

(d)

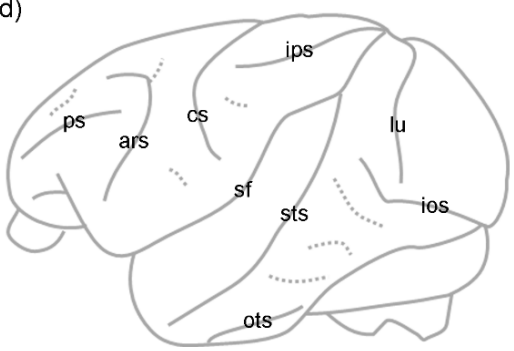

Figure 2. Eternal surface and sulcal map of the left and right cerebral cortex in cynomolgus macaques. (a) Photograph of the right hemisphere. (b) Photograph of the left hemisphere. (c) Sulcal map of the right hemisphere. (d) Sulcal map of the left hemisphere. ars, arcuate sulcus; cs, central sulcus; ios, inferior occipital sulcus; ips, intraparietal sulcus; lu, lunate sulcus; ots, occipitotemporal sulcus; ps, principal sulcus; sf, Sylvian fissure; sts, superior temporal sulcus. 
One major limitation of our previous study (Imai et al. (2011) [20]) is the use of the "cotton thread" to measure the sulcal length. This method involves placing the cotton thread directly onto the cerebral surface to measure the lengths of each sulcus. However, this method cannot be used to obtain other information besides the sulcal length, e.g., the sulcal depths and surface areas. The sulcal depth, rather than the sulcal length, is known to be a susceptible mediator for evaluating the contributions of environmental factors [13]. Bogart et al. (2012) [29] conducted an MRI-based morphometrical analysis of primary sulci of macaques. This study used combined data from mixed-sex samples of two macaque species (rhesus and bonnet macaques), because no significant main effects or interactions were identified between either sex or species. Significant population-level asymmetries were obtained by the right-side bias in the sts surface area, but not in depths of any primary sulci. On the other hand, a significant individual asymmetry was revealed by the right-lateralization of the ars depth in macaques [29].

The ars in macaques is infolded in the lateral frontal cortex and putatively has cortical connections to premotor areas associated with arm and laryngeal representations, frontal eye fields, and somatomotor/orofacial areas [54]. Although the cerebral cortex continuously expanded after the completion of primary sulcogyrogenesis in cynomolgus macaques [18] and other primates [5,55], the progression of ars infolding correlated with the cortical expansion [16]. This phenomenon was similar to the late-emerging sulcal groups infolded in multimodal association cortices among cynomolgus macaques [16]. Therefore, the right-lateralization of the ars length and depth may be attributed to factors such as androgens, which are predominantly expressed in postpubertal males. This hypothesis is supported by a previous study showing the right-lateralization of androgen receptor levels in the frontal lobe in male rhesus monkeys, but not in female monkeys [56].

The sts is another sulcus that exhibits significant population-level asymmetries among macaques. A significant rightward asymmetry was revealed in the sts surface area [29]. Asymmetric pattern of the sts length may vary regionally among Old World monkeys, which consisted of three species including rhesus macaques: significantly right-lateralized at the lateral portion, but not at the medial and insular portions of the sts [57]. Intriguingly, the rightward sts asymmetry has not been observed in other families of nonhuman primates such as great apes (including chimpanzees) and New World monkeys (including capuchins and squirrels) [57]. In humans, the sts depth exhibited a significant rightward asymmetry that was relevant to fMRI-defined, right-lateralized voice-selective responses [25,26]. Asymmetric aspects of the sts morphology may be comparable between the Old World monkeys and humans. However, no left/right side differences were identified in the sts morphology among great apes, which suggests the evolutionary discontinuity of the sts asymmetry.

\section{Comparison to Other Nonhuman Primates}

Hopkins and colleagues reported sulcal asymmetry in great apes. They used MRI data from captive chimpanzees (Pan troglodytes) of both sexes to analyze the sulcal asymmetry due to the lack of sex differences in either the sulcal surface area or sulcal depth. The sulcal surface areas and/or sulcal depth were significantly left-lateralized in the fronto-orbital sulcus, superior precentral sulcus (spcs), sf, intraparietal sulcus, inferior postcentral sulcus, and the lunate sulcus [29]. The spcs in chimpanzees comprises part of the anterior border of the premotor cortex, and it is anatomically identical to the ars in macaques [34]. Interestingly, the surface areas and depth of the spcs were left-lateralized in chimpanzees-opposite to the direction of the symmetries in ars length and depth in macaques (right-lateralized) [29]. The precentral corticospinal system was associated with handedness in chimpanzees as well as humans [58]. Population-level right-handedness (preference for the right hand) was observed in both wild and captive chimpanzees [35,36,59]. However, the direction of hand use preference in macaques depended on species; while left-handedness predominated in rhesus macaques, ambidexterity predominated in cynomolgus macaques [37].

More than two-thirds of capuchins, which belong to the New World monkeys, showed a preference for left-hand use. The right-lateralized cs depth was obtained in left-handed, but not right-handed 
capuchins [38,39]. Among baboons, which belong to the genus Papio in the Old World monkeys, right-handed and left-handed individuals were equally prevalent. Additionally, the cs depth was lateralized contralaterally to the handedness in baboons [40]. On the other hand, the length and/or surface area of the cs were lateralized contralaterally to the handedness in humans [21,22]. Although handedness may be associated with the lateralization of cerebral sulci demarcating the precentral gyrus, the direction of preferred hands and the affected sides of sulci vary depending on the primate species. The sulcal asymmetry in the precentral cortex may shift from rightward to leftward after the split between the Old World monkeys and great apes, which may be relevant to the acquisition of the right-handedness.

The asymmetry of the sf has reportedly been positively associated with the asymmetry of the planum temporale (ptp) [28]. The ptp, cytoarchitecturally homologous to Brodmann's area 22, was left-lateralized in the surface area and gray matter volume, particularly among right-handed chimpanzees and humans [41]. A positive association between the sf and ptp asymmetries was also revealed in chimpanzees via the population-level leftward asymmetry of the sf depth and surface area [29]. In the Old World monkeys, the ptp volume was left-lateralized in cynomolgus macaques [42] and baboons [43], but not in rhesus macaques, bonnet macaques, and vervet monkeys [44]. However, there were no obvious asymmetries in the sf length in cynomolgus macaques [20] nor the sf depth and surface area in the mixed brain samples from rhesus and bonnet macaques [29]. On the other hand, the handedness, which altered the ptp asymmetry in chimpanzees and humans [41,45], was inconsistent among macaques [37]. While the ptp may have started to lateralize leftward during the evolution of Catarrhini (the common ancestor of the Old World monkeys, great apes, and humans), the sf asymmetry may reflect the enhancement of the ptp left-lateralization by acquiring right-handedness after the evolution of Hominoidea.

\section{Possible Mediators for Evaluating Sulcal Asymmetry}

One significant strategy for evaluating the sulcal asymmetry is the use of the gyrification index (GI). The GI, which was originally designed by Zilles et al. (1988) [46], is the most commonly used quantitative parameter for evaluating the cortical convolution and better understanding the interspecies differences, ontogeny, sexual dimorphism, and pathological statuses of neurodevelopmental and neurological disorders, as well a linkage with the functional development of particular cortical regions [34]. The GI is defined by the ratio of cortical contours including and excluding sulcal grooves on coronal slices of the cerebrum. Generally, the GI is calculated as the mean value of all coronal slices throughout the cerebral hemisphere. This value is referred to as the "global-GI" in this manuscript. The global-GI is close to 1 in lissencephalic mammals such as rats (1.02) and mice (1.01), while the marked highest value is found in the Pacific pilot whale (5.55). Meanwhile, the global-GI is 2.56 in humans and between 1.78 and 1.81 in macaques [34]. On the other hand, the sulcal-GI is defined by the ratio of the cortical contours including specific primary sulcus to that excluding other sulcal grooves [9]. The sulcal-GI reflects the length, depth, width, and surface areas of specific sulci as well as the local expansion of particular cortical regions. For example, the sulcal-GI is lower when the sulcal width increases, even if no changes are observed in the sulcal length, depth, and surface area [9]. Furthermore, late-emerging sulcal groups infolded in multimodal association cortices showed significant correlations between sulcal-GIs and cortical volumes in cynomolgus macaques [16]. Further studies will be needed to evaluate the sulcal asymmetry using the sulcal-GI to obtain new insights into the brain lateralization of various species of mammals, including primates.

\section{Conclusions}

The gyrification of the cortical regions was associated with evolutionary expansion [16] and was higher in humans (global-GI $=2.56$ ) and great apes (global-GI $=2.17-2.31$ ) compared to the Old World monkeys (global GI $=1.64-2.27$ ) [34]. Although the global-GI was correlated with larger brain size within the primate order $[18,34,55]$, the increasing gyrification occurred regionally rather 
than throughout the entire brain. Particularly, the sulcal infolding has progressed in multimodal association cortices [16]. Therefore, the sulcal asymmetry may reflect the species-related specification of the cortical morphology and function, allowed by the evolutionary expansion in higher primates. On the other hand, morphological and functional lateralization was observed in other brain regions. Several studies have reported on the cerebellar asymmetry in mammalian species such as humans [47], chimpanzees [38], capuchins [38], ferrets [60-62], and dogs [63]. Cerebellar asymmetry is known to involve the large-scale fiber connections, which have a contralateral linkage to the cerebellar hemispheres with the cerebral association cortices [64]. An association between the sulcal asymmetry and the lateralization of other brain regions such as the cerebellum will provide new insights into the evolution of the mammalian brain regarding species-related specialization of the brain morphology and function.

Funding: No funding was received.

Conflicts of Interest: There are no conflict of interest.

\section{References}

1. Rogers, L.J.; Vallortigara, G.; Andrew, R.J. Divided Brains-The Biology and Behaviour of Brain Asymmetries; Cambridge Univ. Press: New York, NY, USA, 2013.

2. Chi, J.G.; Dooling, E.C.; Gilles, F.H. Gyral development of the human brain. Ann. Neurol. 1977, 1, 86-93. [CrossRef]

3. Pillay, P.; Manger, P.R. Order-specific quantitative patterns of cortical gyrification. Eur. J. Neurosci. 2007, 25, 2705-2712. [CrossRef] [PubMed]

4. Sawada, K.; Fukunishi, K.; Kashima, M.; Imai, N.; Saito, S.; Sakata-Haga, H.; Aoki, I.; Fukui, Y. Neuroanatomic and MRI references for normal development of cerebral sulci of laboratory primate, cynomolgus monkeys (Macaca fascicularis). Congenit. Anom. (Kyoto) 2012, 52, 16-27. [CrossRef] [PubMed]

5. Sawada, K.; Hikishima, K.; Murayama, A.Y.; Okano, H.J.; Sasaki, E.; Okano, H. Fetal sulcation and gyrification in common marmosets (Callithrix jacchus) obtained by ex vivo magnetic resonance imaging. Neuroscience 2014, 257, 158-174. [CrossRef] [PubMed]

6. Ferrer, I.; Hernández-Martí, M.; Bernet, E.; Galofré, E. Formation and growth of the cerebral convolutions I. Postnatal development of the median-suprasylvian gyrus and adjoining sulci in the cat. J. Anat. 1988, 160, $89-100$.

7. Wosinski, M.; Schleicher, A.; Zilles, K. Quantitative analysis of gyrification of cerebral cortex in dogs. Neurobiology 1996, 4, 441-468.

8. Sawada, K.; Watanabe, M. Development of cerebral sulci and gyri in ferrets (Mustela putorius). Congenit. Anom. (Kyoto) 2012, 52, 168-175. [CrossRef]

9. Sawada, K.; Aoki, I. Biphasic aspect of sexually dimorphic ontogenetic trajectory of gyrification in the ferret cerebral cortex. Neuroscience 2017, 364, 71-81. [CrossRef]

10. Louw, G.J. The development of the sulci and gyri of the bovine cerebral hemispheres. Anat. Histol. Embryol. 1989, 18, 246-264. [CrossRef]

11. Marino, L.; Connor, R.C.; Fordyce, R.E.; Herman, L.M.; Hof, P.R.; Lefebvre, L.; Lusseau, D.; McCowan, B.; Nimchinsky, E.A.; Pack, A.A.; et al. Cetaceans have complex brains for complex cognition. PLoS Biol. 2007, 5, e139. [CrossRef]

12. Mortensen, H.S.; Pakkenberg, B.; Dam, M.; Dietz, R.; Sonne, C.; Mikkelsen, B.; Eriksen, N. Quantitative relationships in delphinid neocortex. Front. Neuroanat. 2014, 8, 132. [CrossRef] [PubMed]

13. Kochounov, P.; Castro, C.; Davis, D.; Dudley, D.; Brewer, J.; Zhang, Y.; Kroenke, C.D.; Purdy, D.; Fox, P.T.; Simerly, C.; et al. Mapping primary gyrogenesis during fetal development in primate brains: High-resolution in utero structural MRI of fetal brain development in pregnant baboons. Front. Neurosci. 2010, 4, 20.

14. Kochounov, P.; Glahn, D.C.; Fox, P.; Lancaster, J.L.; Saleem, K.; Shelledy, W.; Zilles, K.; Thompson, P.M.; Coulon, O.; Mangin, J.F.; et al. Genetics of primary cerebral gyrification: Heritability of length, depth and area of primary sulci in an extended pedigree of baboons. Neuroimage 2010, 53, 1126-1134. [CrossRef] 
15. Clark, G.M.; Mackay, C.E.; Davidson, M.E.; Iversen, S.D.; Collinson, S.L.; James, A.C.; Roberts, N.; Crow, T.J. Paracingulate sulcus asymmetry; sex difference, correlation with semantic fluency and change over time in adolescent onset psychosis. Psychiatry Res. 2010, 184, 10-15. [CrossRef] [PubMed]

16. Sawada, K.; Fukunishi, K.; Kashima, M.; Imai, N.; Saito, S.; Aoki, I.; Fukui, Y. Regional difference in sulcal infolding progression correlated with cerebral cortical expansion in cynomolgus monkey fetuses. Congenit. Anom. (Kyoto) 2017, 57, 114-117. [CrossRef] [PubMed]

17. Rogers, J.; Kochunov, P.; Zilles, K.; Shelledy, W.; Lancaster, J.; Thompson, P.; Duggirala, R.; Blangero, J.; Fox, P.T.; Glahn, D.C. On the genetic architecture of cortical folding and brain volume in primates. Neuroimage 2010, 53, 1103-1108. [CrossRef] [PubMed]

18. Sawada, K.; Sun, X.Z.; Fukunishi, K.; Kashima, M.; Satio, S.; Sakata-Haga, H.; Tokado, H.; Aoki, I.; Fukui, Y. Ontogenetic pattern of gyrification in fetuses of cynomolgus monkeys. Neuroscience 2010, 167, 735-740. [CrossRef]

19. Liu, T.; Wen, W.; Zhu, W.; Trollor, J.; Reppermund, S.; Crawford, J.; Jin, J.S.; Luo, S.; Brodaty, H.; Sachdev, P. The effects of age and sex on cortical sulci in the elderly. Neuroimage 2010, 51, 19-27. [CrossRef]

20. Imai, N.; Sawada, K.; Fukunishi, K.; Sakata-Haga, H.; Fukui, Y. Sexual dimorphism of sulcal length asymmetry in cerebrum of adult cynomolgus monkeys (Macaca fascicularis). Congenit. Anom. (Kyoto) 2011, 51, 161-166. [CrossRef]

21. Foundas, A.L.; Hong, K.; Leonard, C.M.; Heilman, K.M. Hand preference and magnetic resonance imaging asymmetries of the central sulcus. Neuropsychiatry Neuropsychol. Behav. Neurol. 1998, 11, 65-71.

22. Klöppel, S.; Mangin, J.F.; Vongerichten, A.; Frackowiak, R.S.; Siebner, H.R. Nurture versus nature: Long-term impact of forced right-handedness on structure of pericentral cortex and basal ganglia. J. Neurosci. 2010, 30, 3271-3275. [CrossRef] [PubMed]

23. Fornito, A.; Wood, S.J.; Whittle, S.; Fuller, J.; Adamson, C.; Saling, M.M.; Velakoulis, D.; Pantelis, C.; Yücel, M. Variability of the paracingulate sulcus and morphometry of the medial frontal cortex: Associations with cortical thickness, surface area, volume, and sulcal depth. Hum. Brain Mapp. 2008, 29, 222-236. [CrossRef] [PubMed]

24. Amiez, C.; Wilson, C.R.E.; Procyk, E. Variations of cingulate sulcal organization and link with cognitive performance. Sci. Rep. 2018, 8, 1-13. [CrossRef] [PubMed]

25. Bonte, M.; Frost, M.A.; Rutten, S.; Ley, A.; Formisano, E.; Goebel, R. Development from childhood to adulthood increases morphological and functional inter-individual variability in the right superior temporal cortex. Neuroimage 2013, 83, 739-750. [CrossRef] [PubMed]

26. Bodin, C.; Takerkart, S.; Belin, P.; Coulon, O. Anatomo-functional correspondence in the superior temporal sulcus. Brain Struct. Funct. 2018, 223, 221-232. [CrossRef] [PubMed]

27. Corballis, M.C. The Lopsided Brain: Evolution of the Generative Mind; Oxford University Press: New York, NY, USA, 1992.

28. Cantalupo, C.; Pilcher, D.L.; Hopkins, W.D. Are planum temporale and sylvian fissure asymmetries directly related? A MRI study in great apes. Neuropsychologia 2003, 41, 1975-1981. [CrossRef]

29. Bogart, S.L.; Mangin, J.F.; Schapiro, S.J.; Reamer, L.; Bennett, A.J.; Pierre, P.J.; Hopkins, W.D. Cortical sulci asymmetries in chimpanzees and macaques: A new look at an old idea. Neuroimage 2012, 61, 533-541. [CrossRef]

30. Bonan, I.; Argenti, A.M.; Duyme, M.; Hasboun, D.; Dorion, A.; Marsault, C.; Zouaoui, A. Magnetic resonance imaging of cerebral central sulci: A study of monozygotic twins. Acta Genet. Med. Gemellol. (Roma) 1998, 47, 89-100. [CrossRef]

31. Kasprian, K.; Langs, G.; Brugger, P.C.; Bittner, M.; Weber, M.; Arantes, M.; Prayer, D. The prenatal origin of hemispheric asymmetry: An in utero neuroimaging study. Cereb. Cortex 2011, 21, 1076-1083. [CrossRef]

32. Sawada, K.; Fukunishi, K.; Kashima, M.; Saito, S.; Sakata-Haga, H.; Aoki, I.; Fukui, Y. Fetal gyrification in cynomolgus monkeys: A concept of developmental stages of gyrification. Anat. Rec. (Hoboken) 2012, 295, 1065-1074. [CrossRef]

33. Sakamoto, K.; Sawada, K.; Fukunishi, K.; Imai, N.; Sakata-Haga, H.; Fukui, Y. Postnatal change in sulcal length asymmetry in cerebrum of cynomolgus monkeys (Macaca fascicularis). Anat. Rec. (Hoboken) 2014, 297, 200-207. [CrossRef] [PubMed]

34. Zilles, K.; Palomero-Gallagher, N.; Amunts, K. Development of cortical folding during evolution and ontogeny. Trends Neurosci. 2013, 36, 275-284. [CrossRef] [PubMed] 
35. Lonsdorf, E.V.; Hopkins, W.D. Wild chimpanzees show population level handedness for tool use. Proc. Natl. Acad. Sci. USA 2005, 102, 12634-12638. [CrossRef] [PubMed]

36. Corp, N.; Byrne, R.W. Sex difference in chimpanzee handedness. Am. J. Phy. Anthropol. 2004, 123, $62-68$. [CrossRef] [PubMed]

37. Chatagny, P.; Badoud, S.; Kaeser, M.; Gindrat, A.D.; Savidan, J.; Fregosi, M.; Moret, V.; Roulin, C.; Schmidlin, E.; Rouiller, E.M. Distinction between hand dominance and hand preference in primates: A behavioral investigation of manual dexterity in nonhuman primates (macaques) and human subjects. Brain Behav. 2013, 3, 575-595. [CrossRef] [PubMed]

38. Phillips, K.; Hopkins, W.D. Exploring the relationship between cerebellar asymmetry and handedness in chimpanzees (Pan troglodytes) and capuchins (Cebus apella). Neuropsychologia 2007, 45, 2333-2339. [CrossRef] [PubMed]

39. Phillips, K.A.; Thompson, C.R. Hand preference for tool-use in capuchin monkeys (Cebus apella) is associated with asymmetry of the primary motor cortex. Am. J. Primatol. 2013, 75, 435-440. [CrossRef]

40. Margiotoudi, K.; Marie, D.; Claidière, N.; Coulon, O.; Roth, M.; Nazarian, B.; Lacoste, R.; Hopkins, W.D.; Molesti, S.; Fresnais, P.; et al. Handedness in monkeys reflects hemispheric specialization within the central sulcus. An in vivo MRI study in right- and left-handed olive baboons. Cortex 2019, 118, 203-211. [CrossRef]

41. Hopkins, W.D.; Nir, T. Planum temporale surface area and grey matter asymmetries in chimpanzees (Pan troglodytes): The effect of handedness and comparison within findings in humans. Behav. Brain Res. 2010, 208, 436-443. [CrossRef]

42. Gannon, P.J.; Holloway, R.L.; Broadfield, D.C.; Braum, A.R. Asymmetry of chimpanzee planum temporale: Humanlike pattern of Wernicke's brain language area homolog. Science 1998, 279, 220-222. [CrossRef]

43. Marie, D.; Roth, M.; Lacoste, R.; Nazarian, B.; Bertello, A.; Anton, J.L.; Hopkins, W.D.; Margiotoudi, K.; Love, S.A.; Meguerditchian, A. Left brain asymmetry of the planum temporale in a nonhominid primate: Redefining the origin of brain specialization for language. Cereb. Cortex 2018, 28, 1808-1815. [CrossRef] [PubMed]

44. Lyn, H.L.; Pierre, P.; Bennett, A.J.; Fears, S.C.; Woods, R.P.; Hopkins, W.D. Planum temporale grey matter asymmetries in chimpanzees (Pan troglodytes), vervet (Chlorocebus aethiops sabaeus), rhesus (Macaca mulatta) and bonnet (Macaca radiata) monkeys. Neuropsychologia 2011, 49, 2004-2012. [CrossRef] [PubMed]

45. Hopkins, W.D. Neuroanatomical asymmetries and handedness in chimpanzees (Pan troglodytes): A case for continuity in the evolution of hemispheric specialization. Ann. N. Y. Acad. Sci. 2013, 1288, 17-35. [CrossRef] [PubMed]

46. Zilles, K.; Armstrong, E.; Schleicher, A.; Kretschmann, H.J. The human pattern of gyrification in the cerebral cortex. Anat. Embryol. 1988, 179, 173-179. [CrossRef] [PubMed]

47. Rosch, R.E.; Ronan, L.; Cherkas, L.; Gurd, J.M. Cerebellar asymmetry in a pair of monozygotic handedness-discordant twins. J. Anat. 2010, 217, 38-47. [CrossRef]

48. Kelava, I.; Lewitus, E.; Huttner, W.B. The aecondary loss of gyrencephaly as an example of evolutionary phenotypical reversal. Front. Neuroanat. 2013, 7, 16. [CrossRef]

49. Yeni-Komshian, G.H.; Benson, D.A. Anatomical study of cerebral asymmetry in the temporal lobe of humans, chimpanzees, and rhesus monkeys. Science 1976, 192, 387-389. [CrossRef]

50. Falk, D.; Cheverud, J.; Vannier, M.W.; Conroy, G.C. Advanced computer graphics technology reveals cortical asymmetry in endocasts of rhesus monkeys. Folia Primatol. 1986, 4, 98-103. [CrossRef]

51. Falk, D.; Hildebolt, C.; Cheverud, J.; Vannier, M.; Helmkamp, R.C.; Konigsberg, L. Cortical asymmetries in frontal lobes of rhesus monkeys (Macaca mulatta). Brain Res. 1990, 512, 40-45. [CrossRef]

52. Heilbroner, P.L.; Holloway, R.L. Anatomical brain asymmetries in New World and Old World monkeys: Stages of temporal lobe development in primate evolution. Am. J. Phys. Anthropol. 1988, 76, 39-48. [CrossRef]

53. Heilbroner, P.L.; Holloway, R.L. Anatomical brain asymmetry in monkeys: Frontal, temporoparietal, and limbic cortex in Macaca. Am. J. Phys. Anthropol. 1989, 80, 203-211. [CrossRef] [PubMed]

54. Goulas, A.; Stiers, P.; Hutchison, R.M.; Everling, S.; Petrides, M.; Margulies, D.S. Intrinsic functional architecture of the macaque dorsal and ventral lateral frontal cortex. J. Neurophysiol. 2017, 117, 1084-1099. [CrossRef] [PubMed]

55. Armstrong, E.; Schleicher, A.; Omran, H.; Curtis, M.; Zilles, K. The ontogeny of human gyrification. Cereb. Cortex 1995, 5, 56-63. [CrossRef] [PubMed] 
56. Sholl, S.A.; Kim, K.L. Androgen receptors are differentially distributed between right and left cerebral hemispheres of the fetal male rhesus monkey. Brain Res. 1990, 516, 122-126. [CrossRef]

57. Hopkins, W.D.; Pilcher, D.L.; MacGregor, L. Sylvian fissure asymmetries in nonhuman primates revisited: A comparative MRI study. Brain Behav. Evol. 2000, 56, 293-299. [CrossRef]

58. Li, L.; Preuss, T.M.; Rilling, J.K.; Hopkins, W.D.; Glasser, M.F.; Kumar, B.; Nana, R.; Zhang, X.; Hu, X. Chimpanzee (Pan troglodytes) precentral corticospinal system asymmetry and handedness: A diffusion magnetic resonance imaging study. PLoS ONE 2010, 21, e12886. [CrossRef]

59. Humle, T.; Matsuzawa, T. Laterality in hand use across four tool use behaviors among the wild chimpanzees of Bossou, Guinea, West Africa. Am. J. Primatol. 2009, 71, 40-48. [CrossRef]

60. Sawada, K.; Horiuchi-Hirose, M.; Saito, S.; Aoki, I. Male prevalent enhancement of leftward asymmetric development of the cerebellar cortex in ferrets (Mustela putorius). Laterality 2015, 20, 723-737. [CrossRef]

61. Sawada, K.; Aoki, I. Age-dependent sexually-dimorphic asymmetric development of the ferret cerebellar cortex. Symmetry 2017, 9, 40. [CrossRef]

62. Sawada, K.; Kamiya, S.; Aoki, I. Asymmetry of cerebellar lobular development in ferrets. Symmetry 2020, $12,735$. [CrossRef]

63. Koyun, N.; Aydinlioğlu, A.; Aslan, K. A morphometric study on dog cerebellum. Neurol. Res. 2011, 33, 220-224. [CrossRef] [PubMed]

64. Wang, D.; Buckner, R.L.; Liu, H. Cerebellar asymmetry and its relation to cerebral asymmetry estimated by intrinsic functional connectivity. J. Neurophysiol. 2013, 109, 46-57. [CrossRef] [PubMed]

(C) 2020 by the author. Licensee MDPI, Basel, Switzerland. This article is an open access article distributed under the terms and conditions of the Creative Commons Attribution (CC BY) license (http://creativecommons.org/licenses/by/4.0/). 